\title{
DEVELOPING AND MAINTAINING A HEALTHY FAMILY TODAY
}

\section{DESARROLLAR Y MANTENER UNA FAMILIA SANA HOY}

\author{
Manuel Moral \\ ORCID: https://orcid.org/0000-0002-1301-1644 \\ Associate Professor at Oakwood University, Huntsville, Alabama USA \\ Carlos Chimpén-López \\ ORCID: https://orcid.org/0000-0001-9384-3960 \\ Associate Professor at University of Extremadura, Cáceres, España
}

How to reference this article:

Moral, M. y Chimpén-López, C. (2021). Developing and maintaining a healthy family today [Desarrollar y mantener una familia sana hoy]. Revista de Psicoterapia, 32(119), págs 197-210. https://doi. org/10.33898/rdp.v32i119.477

\begin{abstract}
This article on health families is specific regarding the key aspects about how to develop and to maintain a healthy family in today's world. These key aspects are theoretically reframed in different words and applied to the growth of a consistent family in current times. Other topics are new entries to complete the picture of a strong and vigorous family. To better understand this complex objective, this article first reviews the concepts and theories about family and love, and then review the different theoretical reviews to better understand the contemporary family. These great definitions and foundations will allow making practical applications in the areas of growth, development and maintenance of a healthy family today.
\end{abstract}

Keywords: contemporary family, family health, family life, family theorie.

\section{Resumen}

Este artículo sobre familias saludables es especifico en cuanto a los aspectos clave acerca de cómo desarrollar y mantener una familia saludable en el mundo actual. Estos aspectos clave se reformulan teóricamente con diferentes palabras y se aplican al desarrollo de una familia sólida en los tiempos actuales. Se ofrecen otros temas con nuevas entradas para completar el cuadro de una familia fuerte y eficaz. Para comprender mejor este complejo objetivo, este artículo repasa primero los conceptos y teorías sobre la familia y el amor, para después revisar las diferentes revisiones teóricas para comprender mejor la familia contemporánea. Estas grandes definiciones y fundamentos permitirán hacer aplicaciones prácticas en las áreas de crecimiento, desarrollo y mantenimiento de una familia saludable en la actualidad.

Palabras clave: familia contemporánea, familia saludable, vida familiar, teorías sobre familia. 


\section{The Concept of Family}

A family is composed of a group of people that are members of the family by consanguinity, affinity, or shared residence (Lamanna et al., 2015; Moral, 2018). There are several levels of family. For example, the nuclear family refers to an adult couple and their children whereas the immediate family may include more relationships such as spouses, parents, children, and brothers and sisters (Nichols, 2016). There is also the extended family, which may integrate many members such as grandparents, aunts, uncles, cousins, nephews, nieces, and other relatives in law as well (Lamanna, 2014).

A family is a unit that includes functional and structural aspects. This unit is emotional, practical, economic, and full of purpose; especially, its main goal is supporting and caring between spouses and for both to do as much as they can for their children and close relatives (Lamanna et al., 2015).

\section{The Concept of Love}

This is the key ingredient in a healthy family. The love of the family started first in marriage and also the couple is the pivotal model of love in the nuclear, intermediate and extended families (Carroll, 2016; Lamanna et al., 2015). For this reason, if the spouses show true love, the family will receive a healthy influence that will be beneficial to the whole system. One of the best definitions of love is based on Sternberg's triangular theory of love. According to this notion, the three elements of love are passion, intimacy and commitment (Lamanna et al., 2015; Regan, 2017). If one or more elements is missing the love will not be consummate love. There is the possibility of growing in love from incomplete types to the most mature type. For that purpose, the couple needs to be aware about how both of them think they love (Carroll, 2010).

Another analysis of love was provided by John Allan Lee in 1973 from the perspective of personalities. He classified love in six styles: eros, storge, pragma, agape, ludus, and mania. The last two styles could impact the family in a negative way. Ludus refers to search for recreational sexual partners more than for one serious spouse. Mania indicates strong intensity with extreme jealous and insatiable attention (Lamanna et al., 2015). For example, when one spouse seeks multiple partners (Ludus) he or she risks obtaining sexual transmission diseases. Also, when a partner is exceedingly suspicious (Mania) this situation increases possible fighting. However, in order to understand love properly it could be very helpful to analyze what love is not. The three things that have been examined are martyring, manipulating, and limerence. The first refers to minimizing one's own necessities while providing the other partner's needs. For example, a husband who works too hard to provide money for his family and never takes a vacation to repair his energy. The second means to control your partner using dishonest ways. For instance, a spouse who pleases his or her partner sexually, with the intention of manipulating money to be spent on what he or she wants. The third is a situation of fantasizing 
about being with the beloved one in every kind of situation (Lamanna et al., 2015). For example, a spouse who decides not to eat regularly until their partner returns and they can eat together.

\section{Theoretical Contributions to Understanding Contemporary Family Life}

Families are systems, of which each part is interconnected (Bateson, 1970/2015; Bertalanffy, 1968; Moral, 2018). Hence, every single member influences the others in positive or negative ways thus making dynamic relationships. To support positive changes and development in families, psychotherapy started the branch named family systems therapy. This subdivision underlined family relationships as an essential issue in psychological well-being. This branch is grounded in the study of systems under the name of the systems theory that first originated from Bertalanffy's general system theory during the 1940s (Association for Advanced Training, 2020; Bertalanffy, 1968). Later on, this notion was applied to other fields like the brain, the person and the family. Bateson and his colleagues applied the systems theory as a great tool for understanding how families work in units (Bateson, 1970/2015; Lamanna, 2014; Nichols, 2011).

\section{The Complexity of the Family System Theory}

The system of the family is very complex because it is also composed of other systems. When applying the general system theory, each person is a system as well. Gordon Allport in the 1950s presented a person as a unique whole, which includes physical, emotional, spiritual, and social aspects without neglecting all the personality traits (Allport, 1960). Each individual is able to create his or her own world, to express talents and arts, to solve or create problems and conflicts, and to accept challenges, commitments, and accountability. Thus, when integrating the system of each member of a related group with the purpose of forming a family, the complexity is the key aspect to understand, develop, and maintain this integrated system of systems in a healthy condition (McAdams, 2009).

A healthy family is a unit whose parts are interconnected, but at the same time each member has own personal ideas, dreams, vision, and objectives. How can one support children and elderly aging members as well as positively influence one another while each member is successful as a person? This is the goal of a healthy family life. The complexity of the family system increases when considering homeostasis as the self-regulation that tends to maintain the system in a dynamic stability (Nichols, 2011). Don Jackson during the late 1950s, proposed the conception of family homeostasis. For example, when both spouses have disrespected each other, even though they understand that they must change and begin to implement different communication models, there will still be a tendency to return to their habitual disrespectful practices. Therefore, both of them must be positively intentional in persisting in a new positive lifestyle. The emphasis of this notion of family homeostasis is that dysfunctional patterns have the propen- 
sity to resist good changes, even ones made with heroic efforts (Nichols, 2016). As a result of this tendency, couples and members could remain stuck. Part of the solution to family homeostasis is not to exaggerate this property of conservation, but to evaluate the resources available in family therapy approaches (Association for Advanced Training, 2020).

\section{Resources Available for the Complexity}

Nathan Ackerman, a contemporary of Jackson, viewed homeostasis as allowing the family system to adjust in a controlled way in order to change. From this perspective, homeostasis is dynamic especially in families and is not necessarily static. Thus, psychodynamic family therapy is a valuable resource to improve family interactions and relationships. The system is open to alignments, modification, and to developing new positive patterns (Association for Advanced Training, 2020).

Murray Bowen during the1960s was a dominant figure in family therapy. He developed the extended family systems therapy, going beyond the nuclear or immediate family. Every single member has the ability of being differentiated from the others belonging to the same system. This happens at intellectual and emotional levels (Bowen, 1978; Lee \& Johnson, 2017). To achieve that purpose a professional helps the family to identify the emotional triangles in order to break them. The result of this therapy is to increase maturity and achieve higher levels of differentiation of self from one member to another (Harrison, 2018; Papero, 2014).

Salvador Minuchin during the 1970s developed a new strategy known as structural family therapy. He was convinced that each family is a system with an implicit structure that establishes how family members interact with one another in their dynamic relationships. This approach involves three steps: joining the family, evaluating its structure, and finally, restructuring the family through reframing and transformation (Minuchin et al., 2007). For example, healthy boundaries can help maintain healthy families because each member of the family knows their status, their responsibilities and their privileges without interfering with others.

\section{Attachment Theory in Family System}

Susan Johnson used attachment theory to help in reviewing the dynamics and interactions of family when one partner is critical and complaining while the other is responding with defensiveness and withdrawal. This theory has been effective mainly in marriage therapy (Nichols, 2011). However, John Bowlby was the first who applied this notion to the baby-caregiver bond (Bowlby, 1969). He reasoned that infants who experienced a negative attachment in their relationships with caregivers will internalize those experiences and will correlate them with the same pattern in their adult interactions with friends, parents, or romantic relationships (Berk, 2012; Bowlby, 1969; Nichols, 2011). The three fundamental attachment types are secure, insecure and avoidant. Only the first style has no correlation with problems in adult relationships. The other two styles cause a struggle with negative 
behavior in their interpersonal interactions (Lamanna et al., 2015).

Two of the main contributions of the attachment theory for healthy families are the following. First, to encourage parents to develop a secure style with children especially during infancy. This is also in agreement with the psychosocial theory of Erickson (1902-1994), in which the infant builds trust versus mistrust from the point of birth to one-year-old. A second contribution is to help adult people to identify a problematic attachment style with the purpose of learning how to change it by using individual or relationship therapy (Berk, 2012; Nikulina \& Widom, 2014; Pournaghash-Tehrani, 2011).

\section{Particular Position in Contemporary Family Life}

Confusion as to the purpose of this particular position in a family, alternately known as purpose, status or place in a family, can ultimately lead to its dissolution (Adler, 1963; Haley, 1981). Each member of the family needs to find a particular position in the system. The status or the role of each particular parent is important and not the same. Alfred Adler directed special attention to the order of birthday, which, according to him, determines many things in every person (Adler, 1963). After this, there was a tradition in Family Therapy which highlighted the importance of birth position in relation to certain problems. Generally, the middle child was the one most associated with rebelliousness issues (Haley, 1981). It is not necessary to take the order of birth into deep consideration. However, it is practical to pay some attention to this matter (Ivey et al., 2007). For example, parents commonly pay great attention to the firstborn. This may influence to become a leader in the future. Frank Sulloway (1996) put strong emphasis on the birth order as an impact on each person. This author wrote an interesting book titled: Born to rebel: birth order, family dynamics, and creative lives (cited in McAdams, 2009, p. 228).

\section{Factors Leading to Family Problems: The Main Threats to Success}

There are major factors that lead to critical family problems and unhealthy conditions. Even when they are not mental disorders, the Diagnostic and Statistical Manual of Mental Disorders (5 ${ }^{\text {thed.; }}$ DSM-5; American Psychiatric Association, 2013) includes them to bring attention to these issues that could interfere with a healthy family. Adult maltreatment and neglect problems between spouses that are not accidental will require professional intervention. Relational problems between parents and children could involve problems related to family upbringing, relationship distress with a spouse or intimate partner, maltreatment and neglect problems such as child physical, sexual, or psychological abuse (Jongsma et al., 2014). All of these require clinical attention and some of them legal attention as well. Sometimes educational problems in children and economic problems in adults affect the family significantly. These conditions could have a substantial influence on the health of the individuals in a family (American Psychiatric Association, 2013; Jongsma et al., 2014). Other factors that could lead to family problems threatening the system are 
the following: miscommunication, lack of sense and purpose, and a boring routine.

\section{Miscommunication}

This is a common problem, which starts small, but can snowball into a massive group of problems ranging from failure to accomplish tasks to abuse. One of the most common forms of miscommunication, and sometimes general lack of communicating, is plainly stated in Gottman's 4 horsemen (Gottman, 2015). Miscommunication caused by anxiety and frustration goes progressively from accusatory tones and harsh criticism to stonewalling that simply severs the communication. Another example is simply ignoring the other spouse till they threaten drastic measures to induce a result (Hooper et al., 2017). While these problems may start with something as simple as failing to vacuum on time or take out the trash when needed, they can quickly escalate into problems on a much deeper level. In turn they have the grave potential to cause separation if left untreated (Carroll, 2016).

\section{Lack of Sense and Purpose}

Purpose is said to improve health and well-being as it acts as a mental fortress against stress by providing a firm feeling of internal support (Regan, 2017). In this sense, anticipatory cognitions refer to individual's ability to formulate life prognoses as an attitude characterized by an intention to understand (Barreira et al., 2001). The positive or negative meaning of these cognitions will affect expectations of the couple. When there is lack of sense and purpose in a family appear a connection between the different projects as a family and a vision of a negative meaning on themselves.

Moreover, it is impossible to accurately assess where stress factors will come from as well as safeguard against every unpredictable event that appears. These factors pose a viable problem for those who lack drive and purpose, which makes it virtually impossible to properly divide and handle resources in response to stress. More so, such immense stress causes havoc in ones' internal framework and mental fortitude. Understanding an individual's place in the world with their life in chaos is unreasonable (Windsor et al., 2015).

\section{Boring Routine}

Slipping into a routine can be a good or bad thing. However, in a relationship allowing the rest of life to take over completely and failing to bring even a slight bit of excitement into the relationship will put it on a sure path to destruction. Lack of passion and desire can indicate that you no longer care enough to put time into the relationship. Many times, couples forget to fulfill each other's emotional needs, not because they feel malice or discontent, but simply because they have been overwhelmed by their other responsibilities and have forgotten. While this is not justification, it is an explanation geared to stimulate understanding. However, if one is not considering the basics of what a relationship needs simply because it is not a 
priority, then the relationship is in desperate need of reevaluation (Gottman, 2015).

The following questions provide examples that should be asked by professionals in evaluation of if the relationships have fallen into listless monotony or not. Does the couple take part in small activities together with joy? Is spending free time together pleasant and something to anticipate? Are they glad to see each other after the day is finished? Are they interested in what was said and do they continue conversation enthusiastically? If after considering these questions one is confused because this has never been a cause for concern, then that could be considered exceptionally good because the couple possesses intimacy on multiple levels. However, it could also be considered tremendously horrible because the spouse in question has never put in enough time or emotions to even consider what the other needs (Regan, 2017).

\section{Factors Leading to Family Health}

There are many factors that could be considered. This article is reviewing those that are more essential to the health of the entire system and its individual member as well. These factors are the following:

\section{Interpersonal Relationships in Marriage}

There are principles for positive relationships during marriage as the first stage of the family that constitutes the foundation of the nuclear family. It is a myth that communication itself is a recipe for a stable, durable, and happy marriage because when conflicts arrive, neither party is listening to the other and then the communication channels get damaged (Cowan \& Hetherington, 2016; Gottman \& Gottman 2019). Sometimes, active listening brings solutions with positive feedback (Gottman, 2015). However, what is more important is to repair in an effective way, learning the principles for making a marriage work. It is key to know how to treat differences with respect and honor. Issues such as gender, culture, religion, and personality could define these differences. The next step will be to allow your partner to influence you with his or her differences. This will make it possible to overcome gridlock and to get a sense of transcendence (Lamanna et al., 2015).

\section{Interpersonal Relationship with Children}

Parents should practice with children positive verbal and affective communication to develop familial and social relationships starting with the first stage of a baby. During the school years parents should involve teachers and educators when communicating about their children and should use cooperation to promote healthy communication (Berk, 2012; Favez et al., 2012). Adolescence many times involves an identity crisis as one is searching for his or her role according to Erik Erikson's psychosocial theory (Berk, 2012, Lamanna et al., 2015). During this period, parents should be open with children in exchanging new information and sharing new realities that could scare them, causing both anxiety and fear (Xiao et al., 2011). 
Adolescence is a critical time in human life. Parents that were doing great in relationships with their children frequently are failing when their children become adolescents (Berk, 2012). Many aspects change in the teenager's life from childhood to preadolescence. For example, adolescents may be identified their selves and showing fidelity to their parents, or they may be confused about themselves and display rebellious behavior to their father and mother (Association for Advanced Training, 2020). These changes continue happening in a drastic way more and more from early, to middle, and late adolescence. Parents often disconcert in front of these quick and sometimes abrupt changes due to the growth and hormonal development of their teenagers. These young people usually exhibit a high level of stress looking for identity, searching for meaning of life, and are eager to discover their role in the demanding contemporary society (Walsh, 2014).

\section{Assertive Communication}

Communication is a process for transferring and receiving information, feelings, understanding, and acceptance in order to move forward to dreams, goals, and plans (Cowan \& Hetherington, 2016). It involves different levels from superficial to deep. The high level of communication brings satisfaction, harmony, and happiness among family members. The nuclear family communication just started with the couple, probably when they married. During this stage the focus was the romantic love and the adaptation to one another (Volling, 2012). However, marital communication changes from marriage to family when the first child is born. Both spouses should make adjustments from their prior topics and views to effectively communicate with a new member of the system. If the family continues gaining new members, new adjustments will be required for healthy communication. The systems need to balance their structure while interacting with familial dynamics (Xiao et al., 2011).

\section{Healthy Financial Patterns}

Money is representative of a wide variety of deeper issues in a relationship and even on a personal level (Gottman \& Gottman, 2019; Lamanna et al., 2015). Money often times represents an individual's desire for security, power, or both. To create healthy financial patterns, one must learn how to balance freedom and commitment (Feeney \& Collins, 2014). What is the balance between saying on the one hand, this is my money that I earned and on the other hand saying, I am responsible for my family whose members have needs and dreams perhaps different from mine? Each person has his or her own story about how he or she understands money. the individuals' story should be put in the context of how the other members of the family understand money (Gottman \& Gottman, 2019). An interpersonal consensus of love and respect may be positively functional. Finances can provide pleasure and protection, and in a relationship, it can be especially hard to make both of these a reality in a consistent manner. One such reason is because money has such 
a diverse meaning and purpose to each unique person in its own way. Early in a relationship, a majority of financial problems are considered solvable (Symoens et al., 2014). However, as the relationship progresses and the financial changes in question involve more money, assets, and family members, it can become increasingly difficult to resolve them. This being said, as a couple ages one of two things will happen, either the circumstances will have been solved with time, or else they will become a source of constant and repetitive strain on the relationship. Either way it becomes necessary to take children, education, housing, job opportunities and the economy into account when making any type of financial decision (Chiu, 2017).

There is a plethora of techniques that can be used to improve financial wellbeing. This can include but is not limited to: Itemizing your current expenditures by listing all of your past and current uses of money. Management of everyday finances by taking the previously mentioned list and considering every item on it carefully and placing them into a category, such as essential and non-essential. Coming up with a plan to consistently pay bills, such as who is in charge of payment and delivery of the billed amount. These are only small examples of what can be done to begin the improvement of the families' handling of finance (Elbogen et al., 2011).

\section{Healthy Sexuality}

In order to obtain a healthy sexuality, the couple must have a strong understanding and acceptance of each other on a fundamental level. As Gottman (1999) so aptly stated, "No other area of a couples' life offers more potential for embarrassment, hurt, and rejection than sex" (p. 200). In many cases it has been found that when conversations come up based on the topic of sex and intimacy, the couples are extremely vague and appear to want the conversation over with as quickly as possible. They seldom convey their emotions with clarity and decisiveness. This only leads to the problem continuing without any real resolution (Feeney \& Collins, 2014). There are types of communication that can be avoided in order to strengthen intimacy and sexuality in a relationship. Some aspects that should be avoided are indirect, imprecise, and inconclusive conversation. If the couple learns how to talk to each other, however, in particular about this delicate topic, the sexual intimacy and identity can be improved with leaps and bounds (Carroll, 2016).

Healthy sexuality in a relationship requires the couple to be understanding of the vulnerable state that they both are in, and to find a suitable response to each spouse's requests and desires. When tackling this topic, one may show finesse as well as passion, being gentle and considerate while taking into account that it is acceptance and love that both spouses desire (Regan, 2017). The purpose of sexual intimacy is simply to create a bond between the couple, having fun, feeling pleasure and seeing the satisfaction each partner brings to the other (Carroll, 2016). All of this brings the couple into a closer more loving relationship. It also creates a feeling of value and belonging between the two. This is a delicate strength that may be sought by both partners for the sake of their relationship (Hernandez et al., 2011). 


\section{Unity Throughout Diversity}

Differentiation of self refers to the ability that individuals possess to separate the emotional functioning from the cognitive performance (Association for Advanced Training, 2020; Bowen, 1978). This ability is first developed in the nuclear family and its levels continue establishing throughout the extended family and all the other relationships (Harrison, 2018). For example, if one of two spouses develops a higher level of differentiation of self, that individual will be able to better manage their emotions in their interactions with that person. On the contrary, if the level of differentiation of self is low, the tendency will be to develop a partner attachment with a co-dependency that will make him or her difficult to face the challenges of daily life (Moral, 2018). This is also applicable to the relationship among parents and children.

Differentiation of self can aid in the production of individuality of both personal identity and future and present goals. Not all the members of the nuclear family are the same, though they may share various attributes. This can make a fundamentally diverse and strong constitution in the family (Bowen, 1978; Kerr \& Bowen, 1988). This can be called interconnection, or a personally validating and supportive form of teamwork that is comprised of set supportive roles in a family group. This can allow individuals in a family to function individually, while at the same time creating strong bonds and support habits that procure a more effective way of reaching goals as a family unit (Minuchin et al., 2007). Avoiding meshing can be a far more problematic task than one may have originally anticipated. As the name implies, meshing is the point at which the use of family structure as a support system to achieve goals turns into a dependence that prevents further growth (Lamanna et al., 2015).

\section{Cultural Influences}

Culture has two aspects. The first aspect determines the surface culture, the objective factors that are the product of people group endeavors such as food, holidays, arts, folklore, history, dress, and heroes (Peleg \& Rahal, 2012). The second aspect makes up the deep culture and includes the objective factors such as thoughts, beliefs, and actions of a people group based on aesthetics, ethics, precedence, gender, roles, religion, use of space, things considered taboo, use of time, sense of ownership, concepts of normality and wellness and communication style. Culture is a very complex concept that combines external and internal factors (Peleg \& Rahal, 2012). For this reason, each group has its own culture, but there also could be different variations among members of the same culture. The members of the family could be from different cultures. For a healthy family, there is a need of interpreting correctly members from diverse cultures (Organista et al., 2010).

Culture is a coordinated way of sharing life that is transmitted to each new generation. In this process of transmission, the patterns of thought and behavior undergo changes, adjustments and even transformations (Moral, 2018). Therefore, 
culture should not be considered as a static but a dynamic notion with constant interactions among individuals, families and society (Association for Advanced Training, 2020). Families are in transitions and constant reorganization (Cowan \& Hetherington, 2016). The cultural dynamism of families can positively or negatively impact the interactions between families and, specifically, with the new forms and types of family that exist such as single parent, homoparental, rainbow, etc (Lamanna et al., 2015). It is not necessary to agree with everything or everyone in the family, but it is healthy to express sympathy and even more to show empathy that develops compassion and understanding through diversity and differences.

\section{On Family Structure and Relationships}

Family members should be aware if there are cultural differences among the members of the nuclear, immediate, and extended family. It is great to educate each member to understand, respect, and facilitate cultural variations that could range from mild to strong (Bowen, 1978). However, it is possible only with empathy, and some knowledge about each culture related to the particular family. Families do not change culture (Haefner, 2014). Nevertheless, they are helping their members through cultural diversity looking for an ideal macro-culture that wants pluralism, which means that everyone can preserve his or her own culture and live in a peaceful family with other cultural backgrounds and at the same time interchange and borrow values, customs and beliefs (Organista et al., 2010).

\section{Summary and Conclusions}

Family therapy originated during the 1950s from Gregory Bateson. However, the dominant figure on this theory is Murray Bowen throughout the 1960s to 1990s because he was the first to develop the revolutionary Family Systems Theory. Bateson, Bowen and others defined the family through a systemic worldview (Bowen, 1978; Papero, 2014; Torres, 2016).

If one understands how the whole family works, it is possible to understand each specific member of that family. This perspective takes into account theories, relationships, status, roles, and negative and positive factors that affect the system. The purpose is to have a healthy functioning family. This notion could be applied to improve the quality of life of the family because all the members are affecting one another (Ivey et al., 2007).

Naturally the factors mentioned are simply a small fraction of the immense number of negative circumstances that can affect a relationship and damage a family. However, all of these can be seen as lead-ins to other lesser and greater problems, such as infidelity, abuse of various natures, and even suicide in some cases. Conversely, it can be seen that when there is a lack of communication, passion, supportiveness and understanding of one's internal struggles and needs, that the relationship is in dire need of both individual and family counseling (Arnocky et al., 2015). 
Once again it can be said that these are only a limited few of the aspects of relationships that can help create a healthy family. It can be said however that these make up some of the stronger fundamentals. Family structure, parental relationship modeling, and proper use of finance are the basics needed for the building of a strong, connected and loving family unit (Gottman \& Gottman, 2019; Lamanna et al., 2015).

From the theoretical frameworks discussed early Ackerman emphasizes that the system of the family is dynamic with transitions from generation to generation. Thus, it is recommended to preserve open this system without interfering the capacity of communicating throughout giving positive output and receiving affirmative input (Association for Advanced Training, 2020; Moral, 2018).

If members of the family have good psychological health, they may at the same time be aware of cultural differences of some members of the entire family. It is recommended that a healthy family should develop intercultural and multicultural skills, not only with information but in a practical way, knowing especially about those cultures that are related to a specific family (Organista et al., 2010). A healthy family is grounded on love, respect, assertive communication, reciprocity, complementarity, proximity, growth and development; all of these interconnected throughout diversity, similarities and differences.

\section{References}

Adler, A. (1963). Individual psychology. Littlefield, Adams, \& Company.

Allport, G. W. (1960). The open system in personality theory. The Journal of Abnormal and social Psychology, 61(3), 301-310. https://doi.org/10.1037/h0043619

American Psychiatric Association (2013). Diagnostic and statistical manual of mental disorders: DSM-5 (5 ${ }^{\text {th }}$ ed.). https://doi.org/10.1176/appi.books.9780890425596

Arnocky, S., Sunderani, S., Gomes, W., \& Vaillancourt, T. (2015). Anticipated partner infidelity and men's intimate partner violence: The mediating role of anxiety. Evolutionary Behavioral Sciences, 9(3), 186-196. https:// doi.org/10.1037/ebs0000021

Association for Advanced Training in the Behavioral Sciences (2020). Counseling: National counselor exam, volume II.

Barreira, D.P., Cavaglia, F., \& Pires, A.M. (2001). Cognições antecipatórias: Um estudo comparativo e correlacional. Psicol. Saúde Doenças, 2, 101-105.

Bateson, G. (2015). Form, substance and difference. ETC: A Review of General Semantics, 72(1), 90-104. (Original work published in 1970).

Berk, L. E. (2012). Infants, children, and adolescents ( $7^{\text {th }}$ ed.). Pearson.

Bertalanffy, L. (1968). General system theory: Foundations, development, applications. George Braziller.

Bowlby, J. (1969). Attachment and loss: Volume 1: Attachment. Basic Books.

Bowen, M. (1978). Family therapy in clinical practice. The Rowman \& Littlefield.

Carroll, J. L. (2010). Sexuality now: Embracing diversity ( $3^{\text {rd }}$ ed.). Cengage Learning.

Carroll, J. L. (2016). Sexuality now: Embracing diversity (5 ${ }^{\text {th }}$ ed.). Cengage Learning.

Chiu, T. Y. (2017). Marriage migration as a multifaceted system: The intersectionality of intimate partner violence in cross-border marriages. Violence Against Women, 23(11), 1293-1313. https://doi. org/10.1177/1077801216659940

Cowan, P. A., \& Hetherington, M. (2016). Family transitions: Family Research Consortium: Advances in family research ( $2^{\text {nd }}$ ed.). Routledge. 
Elbogen, E. B., Tiegreen, J., Vaughan, C., \& Bradford, D. W. (2011). Money management, mental health, and psychiatric disability: A recovery-oriented model for improving financial skills. Psychiatric Rehabilitation Journal, 34(3), 223-231. https://doi.org/10.2975/34.3.2011.223.231

Favez, N., Lopes, F., Bernard, M., Frascarolo, F., Scaiola, C. L., Corboz-Warnery, A., \& Fivaz-Depeursinge, H. (2012). The development of family alliance from pregnancy to toddlerhood and child outcomes at 5 years. Family Process, 51(4), 542-556. https://doi.org/10.1111/j.1545-5300.2012.01419.x

Feeney, B. C., \& Collins, N. L. (2014). Much “I do" about nothing? Ascending mount Maslow with an oxygenated marriage. Psychological Inquiry, 25(1), 69-79. https://doi.org/10.1080/1047840X.2014.878683

Gottman, J. M. (1999). The seven principles for making marriage work: A practical guide from the country's foremost relationship expert. Three Rivers Press.

Gottman, J. M. (2015). The seven principles for making marriage work: A practical guide from the country's foremost relationship expert ( $2^{\text {nd }}$ ed.). Harmony Books.

Gottman, J. M., \& Gottman, J. S. (2019). Eight dates to keep your relationship happy, thriving and lasting. Penguin Life.

Haefner, J. (2014). An application of Bowen family systems Theory. Issues in Mental Health Nursing, 35(11), 835-841. https://doi.org/10.3109/01612840.2014.921257

Haley, J. (1981). Uncommon Therapy the Psychiatric Techniques of Milton Erickson. Norton.

Harrison, V. (2018). The family Diagram \& Family Research: An illustrated guide to tool for working on differentiation of self on one's family. Center for the Study of Natural Systems and the Family.

Hernandez, K. M., Mahoney, A., \& Pargament, K. I. (2011). Sanctification of sexuality: Implications for newlyweds' marital and sexual quality. Journal of Family Psychology, 25(5), 775-780. https://doi.org/10.1037/a0025103

Hooper, A., Spann, C., McCray, T., \& Kimberly, C. (2017). Revisiting the basics: Understanding potential demographic differences with John Gottman's Four Horsemen and emotional flooding. The Family Journal: Counseling and Therapy for Couples and Families, 25(3), 224-229. https://doi.org/10.1177/1066480717710650

Ivey, A. E., D’Andrea, M., Ivey, M. B., \& Simek-Morgan L. (2007). Theories of Counseling and Psychotherapy: A Multicultural Perspective (6 ${ }^{\text {th }}$ ed.). Pearson.

Jongsma, A. E., Peterson, J. L., \& Bruce, T. J. (2014). The complete adult psychotherapy treatment planner (5 $5^{\text {th }}$ ed.). Wiley.

Kerr, M., \& Bowen, M. (1988). Family evaluation. Norton.

Lamanna, M. A. (2014). Study guide for marriages, families, and relationships (12 ${ }^{\text {th }}$ ed.). Content Technologies.

Lamanna, M. A., Riedmann, A., \& Stewart, S. (2015). Marriages, families, and relationships (5 $5^{\text {th }}$ ed.). Cengage Learning.

Lee, H-H., \& Johnson, R. W. (2017). Assessing the psychometric properties of the Differentiation of Self InventoryRevised for Asian-American bicultural adults. The American Journal of Family Therapy, 45(1), 51-65. https://doi.org/10.1080/01926187.2016.1232611

McAdams, D. P. (2009). The person: an introduction to the science of personality psychology (5 ${ }^{\text {th }}$ ed.). Wiley.

Minuchin, S., Nichols, M. P., \& Lee, W-Y. (2007). Assessing families and couples: from symptom to system. Allyn and Bacon.

Moral, M. (2018). The relationship between differentiation of self and psychological adjustment to separation (Publication No. 13424258) [Doctoral dissertation in the Northcentral University San Diego-California]. ProQuest Dissertation and These Global.

Nichols, M. P. (2011). The essentials of family therapy (5 ${ }^{\text {th }}$ ed.). Pearson Education.

Nichols, M. P. (2016). Family therapy: Concepts and practice $\left(11^{\text {th }}\right.$ ed.). Pearson.

Nikulina, V., \& Widom, C. S. (2014). Do race, neglect, and childhood poverty predict physical health in adulthood? A multilevel prospective analysis. Child Abuse \& Neglect, 38(3), 414-424. https://doi.org/10.1016/j. chiabu.2013.09.007

Organista, B. B., Marín, G., \& Chun, K. M. (2010). The psychology of ethnic groups in the United States. Sage.

Papero, D. V. (2014). Assisting the two-person system: An approach based on the Bowen Theory. Australian and New Zealand Journal of Family Therapy, 35(4), 386-397. https://doi.org/10.1002/anzf.1079

Peleg, O., \& Rahal, A. (2012). Physiological symptoms and differentiation of self: A cross- cultural examination. International Journal of Intercultural Relations, 36(5), 719-727.https://doi.org/10.1016/j.ijintrel.2012.04.001

Pournaghash-Tehrani, S. (2011). The role of beliefs, attitudes and adverse childhood experiences in predicting men's reactions towards their spouses' violence. Journal of Family Violence, 26, 93-99. https://doi. org/10.1007/s10896-010-9345-1

Regan, P. C. (2017). The mating game: A primer on love, sex, and marriage ( $\left.3^{\text {rd }} \mathrm{ed}.\right)$. Sage.

Sulloway, F. J. (1996). Born to rebel: birth order, family dynamics, and creative lives. Pantheon Books. 
Symoens, S., Van de Velde, S., Colman, E., \& Bracke, P. (2014). Divorce and the multidimensionality of men and women's mental health: The role of social-relational and socio-economic conditions. Applied Research Quality Life, 9, 197-214. https://doi.org/10.1007/s11482-013-9239-5

Torres, P. (2016). Burnout and stress in child protection workers: The moderating role of differentiation of self (Publication No. 10105308) [Doctoral dissertation in the Northcentral University, Prescott Valley]. ProQuest Dissertation and These Global.

Volling, B. L. (2012). Family transitions following the birth of a sibling: An empirical review of changes in the firstborn's adjustment. Psychological Bulletin, 138(3), 497-528. https://doi.org/10.1037/a0026921

Walsh, D. (2014). Why do they act that way? A survival guide to the adolescent brain for you and your teen $\left(2^{\text {nd }}\right.$ ed.). Simon \& Schuster.

Windsor, T. D., Curtis, R. G., \& Luszcz, M. A. (2015). Sense of purpose as a psychological resource for aging well. Developmental Psychology, 51(7), 975-986. https://doi.org10.1037/dev0000023

Xiao, Z., Xiaoming Li, X., \& Stanton, B. (2011). Perceptions of parent-adolescent communication within families: It is a matter of perspective. Psychology, Health \& Medicine, 16(1), 53-65. https://doi.org/10.1080 /13548506.2010.521563 